variations. There is considerable scope for experiment in this field.

When planning residential accommodation, the architect should consult fully with the university authorities and with student representatives to ensure that the most economic as well as the most effective lay-out is obtained, encouraging the corporate spirit of the university as well as facilities for private study and relaxation of the individual student.

Since the provision of enough residential places is economically unattainable in the near future, the Union emphasizes that not all forms of lodging are necessarily suitable for students, who need a quiet room for study, flexible hours and a sympathetic atmosphere. Lodgings that may suit some purposes can be quite unfitted for study. In a small town such as Aberystwyth, where the university dominates the life of the community, students often find that landladies come to understand their needs and take a real interest in providing the right environment for study. If the university atmosphere and community is to develop, all accommodation should be in close proximity to the university centre.

Another important factor is the academic and administrative structure of the university. Apart from the fact that this can determine the success or failure of its development as a community, it will have repercussions on the breaking down of faculty or departmental inter-relationships, which is already taking place through increased specialization ; it will also affect the balance of Faculties and of undergraduate/postgraduate ratios. The structure most conducive to a fully integrated university education is the collegiate structure as will be developed at Bristol. In the expansion of existing universities it may well be desirable to avoid the piecemeal addition of extra sections to the present structure, but rather to change to the collegiate pattern.

All the major buildings of the university--halls. union building, laboratories, libraries, lecture theatres and refectories should be grouped together on one site. It would be valuable if a few small buildings in the various towns selected as new university sites could be leased to the university for use as, say, libraries for the smaller Faculties, and as staff houses where some tutorials could be given; arrangements might also be made for the designation of a university ehurch within the town. Such facilities should not be allowed to detract from the ereation of a single university unit.

There should be some degree of specialization in each university in selected areas of study. Such specialization could build up a reputation, encourage research, simplify application problems, attract interested staff, and might also prevent duplication of capital costs on research equipment. Development should be considered in relation to the paramount need to operate a proper tutorial system.

The major need of students is adequate provision for the development of an active student community. There should be a Students' Union building, providing a meeting place and a centre of student life, which should, where possible, be a separate building.

Where new laboratories are being erected, these should be designed in conformity with good safety regulations. It is also hoped that the need for an adequate and well-equipped clinic is generally recognized. These are already provided in many universities, and will be essential in new universities where the treatment of physical or mental illness should not be left to the care of local doctors who might not be readily accessible.

\title{
SENSORY SPECIALIZATION IN RESPONSE TO ENVIRONMENTAL DEMANDS
}

$\mathrm{T}$ THE third of a series of Zoological Society of London symposia was held on March 4 under the title "Sensory Specialization in Response to Environmental Demands". It was organized by Prof. O. Lowenstein, and the meeting was held under the chairmanship of Prof. R. J. Pumphrey.

In his introductory remarks, Prof. Lowenstein directed attention to the somewhat Lamarckian ring of the title; but he envisaged that none of the topics under discussion would make it necessary or desirable to infringe neo-Darwinian orthodoxy. Outlining the rationale of the programme, he went on to point out that two different types of adaptive specialization could usefully be surveyed in this context. The first may affect the whole range of sensory modalities as a means of adapting an animal to a successful integration into a sub-social or social organization. This type is found, for example, in locusts and to a more extreme degree in the social Hymenoptera. The second type of sensory specialization may be confined to one sense organ only, the eye in nocturnal, deep sea, or cave animals, or the ear in animals like bats and cetaceans which find their way about by means of sonar.

A comparative analysis of sensitivity limits may also reveal instances of adaptation to special environmental circumstances. The sensitivity limits of photo-receptors may serve to illustrate this point.
In a paper on the sensory equipment of the migratory locust, Dr. P. T. Haskell (Anti-Locust Research Centre, London) showed that special sensory adaptations are related to the control of steady and stable flight of the swarming insect and to the maintenance of cohesion between locusts in the swarm. 'Dorsal-light' reaction of the compound eye and proprioceptive feed-back from receptors on the cervical hair plates control anti-roll stabilization, whereas anti-yawing responses are elicited by cephalic hair sensilla. Preferred inter-locust distance in the swarm is maintained by an equilibrium between visual attraction and repulsion in response to auditory and other mechanical stimuli.

Fully social organization as shown by the social Hymenoptera involves a number of instances of extreme sensory specialization in the various castes of ants and bees. Dr. H. Kalmus (Galton Laboratory, University College, London) described some new results concerning colour vision and odour discrimination in the honey bee. Whereas scent is an important item of information in bee-to-bee communication, symbols for colour are very likely missing from the 'vocabulary' of the social insects. A discussion of the mechanism of analysis of the plane of polarized light was illustrated by an electron-micrograph of an insect ommatidium. Dr. Kalmus suggested that the chief sensory adapta- 
tion in the social Hymenoptera consists of a co-adaptation of pre-existing sensory mechanisms with patterns of motor activity into systems of communication.

In a paper on the sensitivity limits of photoreceptors, Dr. F. H. C. Marriott (Department of Physiology, Oxford) stressed the necessity of presenting measurements of spectral and absolute threshold sensitivity in such a form that they can be compared throughout the animal kingdom. Such measurements made on five species, namely, man, cat, owl, the amphibian Xenopus, and the flatworm Dendrocoelum, were discussed and compared with special reference to the differences in the visual sensory structures.

Dealing with the problems of the sensory aspects of adaptation in cave animals, Dr. G. Thines (Laboratory of Experimental Psychology, University of Louvain) gave a paper on sensory degeneration and survival in cave fishes. After a critical discussion of the general idea of evolutionary 'progress', Dr. Thines defined regressive changes as a gradual reduction of independence leading to the 'abnormal' character of regressive faunas such as cave fishes. The survival value of regressive changes in photoreceptors in cave fishes was then assessed and this led to the introduction of the hypotheses of 'reman. ence' and 'vicariance' with regard to the significance of the continuation in eyeless cave fishes of the pre-existing epigean photokinetic functions and of the supplanting of the functionally insufficient eye by the pineal organ. Dr. Thines then showed a short film on the blind fishes of Somaliland.

The design of fish and cephalopod eyes in relation to their environment was discussed by Dr. E. J. Denton (Marine Biological Laboratory, Plymouth). The density, the refractive medium, absorption and scattering of light by the medium all have their effect on the morphology and functional characteristics of the eyes of marine animals. At greater depth and at night the light emitted by luminescent animals may be more important than the light coming from the sky. Light will only be 'useful' for vision if it can be absorbed by photosensitive pigments. Pigments then play an important part in the adaptive specialization of eyes. The elongation of the rods of the deep-sea fish retina, although raising sensitivity, could have an adverse effect on visual acuity were it not for the existence in these elongated rods of marked channelling of light along the rod, Pigment migration between rods also diminishes the blurring effect of lateral spread of light.

The symposium ended with an account by Prof. F. P. Möhres (Department of Comparative Physio. logy, University of Tübingen) on sonic orientation of bats and other animals. Prof. Möhres recounted how, during the Second World War, Spallanzani's classical observation of orientation of bats in the dark found its explanation in the simultaneous discovery of ultrasonic echo-location in the vespertilionid bats by Griffin, Pierce and Galambos in the United States, by Dijkgraaf in Holland and by himself in Germany, all of them confirming a hypothesis advanced by Hartridge in 1922. In vespertilionid bats short volleys of ultrasonic pulses of a broad and irregular frequency spectrum are utilized in a system of time difference estimation in which the time difference between the emitted signal and its returning echo is a measure of the distance of the reflecting object, and the $\operatorname{tim} \theta$ difference between the arrival of the echo at the two ears serves as a measure of direction. A completely different sonar mechanism of orientation was, how. ever, discovered by Prof. Möhres to exist in the horse-shoe bats (Rhinolophids). While flying, the horse-shoe bats keep their mouths closed and the horse-shoe points in the direction of flight, or in stationary animals into the direction of 'interest'. Ultrasonic sound, consisting of prolonged cries without frequency or amplitude modulation, is ernitted through the nostrils and cast about in a beam 'focused' by the horse-shoe. In Rhinolophids the essential feature of ultrasonic orientation is thus, according to Prof. Möhres, not a time difference but an intensitydifference estimation. The animals are thus believed to assess the sound intensity of their orientation cries reflected by objects in their environment in turning their ears point to point through the range of space under scrutiny. Rendering the ears immobile abolishes successful orientation. It must be mentioned here, however, that certain aspects of the modus operandi of sonar as summarized by Prof. Möhres are meeting with adverse criticism from a number of quarters.

Finally, Prof. Möhres described how a search for mechanisms intermediate between the vespertilionid and the rhinolophid extremes led to the discovery of intermediate situations in the Hipposideridae and the Megachiroptera (fruit bats). However, no conclusive phylogenetic picture emerged, and the origin and ways of the evolutionary lines remain hidden in the darkness of the past.
O. Lowenstein

\section{ASPECTS OF OROGENS}

$\mathrm{T}$ HE Geologische Vereinigung held its fiftieth anniversary meeting under the presidency of Prof. G. Fischer in Würzburg during March 12-14. The theme for discussion was the Orogen, the mobile belts or those parts of the Earth's crust in which mountain chains are formed. 'The process of orogeny can best be considered in respect of time; a time when the materials accumulate and become compacted to form the building materials for the mountains ; a time when these rocks are disturbed by forces usually regarded as being produced by shrinking of the Earth's surface; and a time when magmas from deeper horizons within or below the crust break through and pierce the strata whether quiet or crumpled and broken. Part of the magmatic activity consists of the release and movement of reagents which metamorphose the sediments. Then comes a final act in which vertical movements are considerable, helping to account for the present stature of the mountains and their wild or orderly scenery by exposing the various structures to erosion.

There is also a space relationship. The orogens are restricted to comparatively narrow belts in which mountain building takes place. The arrangement of the mountains within these belts is not simple or regular. One reason for this is that earlier chains may have stood along or across the line followed later by younger mountains, and their presence, or that of 